\title{
Myles Brand, My Father
}

\author{
Josh Brand \\ Senior Director of Corporate Learning, Harvard Medical School
}

When I was growing up, my father had a chair in the living room. It was a comfortable leather reclining chair with a small ottoman. He placed it in a corner of the room so he could see whatever action was going on in the house, and so he could look out the big picture window at the Sonoran desert and mountains. That's where he did his work. He didn't have a desk, he had a chair. As a Philosophy professor, it's where he wrote his books - longhand, double spaced in pencil on yellow legal pads. Later, it's where he wrote his speeches as a university and NCAA president. The chair was usually surrounded by books, letters and many pieces of written-on yellow paper. There was the neat pile of paper, which were the 'keepers', and there were the hastily folded in half pieces of paper flung onto the ground. These were the 'rejects'. Every so often, when the keeper pile was sufficiently high, my father would emerge from his chair and want to talk - or more accurately debate - whatever he was working on. We would have these discussions in the car, while riding our horses through the desert outside Tucson, or just hanging out around the house. It was just my father, me and my stepmother Peg in the house. Because Peg had her own work to do and I was a teenager with plenty of idle time, I was often the only one available for these discussions.

To the outside world, my father was a public figure and a leader. He set strategy, he gave speeches and he led organizations through crises. There always seemed to be a crisis to deal with. From the living room, what I saw was a man who was happiest, most relaxed, and most himself when he was solving problems and learning something new. I think part of what drove him to the heights of his profession was the promise of new things to learn and new challenges to meet. When confronted with a challenge, he went into learning mode. What do I need to learn and from whom do I need to learn to meet this challenge? A little later in life, when I was pursuing my MBA, he took great interest in my studies. He borrowed my Marketing textbook, and probably read more of it than I ever did.

Whether by nurture or nature or some of both (we would often have that particular debate), I owe much of who I am today to being part of my father's life, and I have tried to pay that forward to my own daughters. As I sit in my living room chair typing this out on my laptop (some things change), I know he would be happy to see Peg taking on the challenge of this journal, and I hope that he would be happy with the pursuit of challenges and learning I have chosen in my life. 